\title{
Relationship between time management skills and anxiety and academic motivation of nursing students in Tehran
}

\author{
Arezoo Mohamadkhani Ghiasvand ${ }^{1}$, Manijeh Naderi ${ }^{2}$, Mansoureh Zagheri Tafreshi ${ }^{3}$, Farzane Ahmadi $^{4}$, \\ Meimanat Hosseini ${ }^{5}$
}

${ }^{1}$ M.Sc. Student of Nursing, School of Nursing \& Midwifery, Shahid Beheshti University of Medical Sciences, Tehran, Iran

${ }^{2}$ M.Sc. of Nursing, Instructor, Department of Nursing Management, School of Nursing \& Midwifery, Shahid Beheshti University of Medical Sciences, Tehran, Iran

${ }^{3}$ Ph.D. of Nursing, Associate Professor, Department of Nursing Management, School of Nursing \& Midwifery, Shahid Beheshti University of Medical Sciences, Tehran, Iran

${ }^{4}$ Ph.D. Student of Biostatistics, Department of Biostatistics School of Paramedical Medicine, Shahid Beheshti University of Medical Sciences, Tehran, Iran

${ }^{5}$ Ph.D. of Nursing, Assistant Professor of Community Health Nursing Department, School of Nursing and Midwifery, Shahid Beheshti University of Medical Sciences, Tehran, Iran

\section{Type of article: Original}

\begin{abstract}
Introduction: Time management skills are essential for nursing students' success, and development of clinical competence. The purpose of this study was to determine the relationship between time management skills and anxiety and academic motivation of nursing students in Tehran medical sciences universities in 2015.

Methods: This cross-sectional study was carried out on 441 nursing students in three medical universities in Tehran. Random stratified sampling was done to select the samples. Data were collected using demographic Questionnaire, Time Management Questionnaire (TMQ), Spielberger State-Trait Anxiety Inventory (STAI) and Academic Motivation Scale (AMS), which was completed t by self-report. Data were analyzed using SPSS 18 software with descriptive and analytical statistics such as ANOVA, independent $t$-test, Regression and Pearson Correlation Coefficient.

Results: Most participants had a moderate level of time Management skills (49\%), State Anxiety (58\%), Trait Anxiety (60\%) and Academic Motivation (58\%). The results also showed a statistically significant negative correlation between the students' TMQ scores and the state anxiety $(\mathrm{r}=-0.282, \mathrm{p}<0.001)$ and trait anxiety scores $(r=-0.325, p<0.001)$. Moreover, there was a statistically significant positive correlation between the students' TMQ scores and AMS scores $(r=0.279, \mathrm{p}<0.001)$.

Conclusion: Regarding the findings, it seems that it is necessary to plan for improving time management skills in order to enhance academic motivation and reduce anxiety rates among nursing students.

Keywords: Time management, Anxiety, Academic motivation, Nursing students
\end{abstract}

\section{Introduction}

Time is considered the most valuable commodity in our lives, and the development of other sources are dependent on the presence and availability of time (1). The key to reaching success in life is to concentrate on effective time management (2). Behavior of time management was first defined in late 1950. Time management means to optimally use the time available (3) and that includes aspects of planning, goal setting, prioritizing goals and activities, communications and delegation (4). Individuals can carry out several tasks, perceive their responsibilities and adapt with limitations by managing themselves in a single time through such behavior (5). Time management is

\section{Corresponding author:}

Manijeh Naderi, Department of Nursing Management, School of Nursing \& Midwifery, Shahid Beheshti University of Medical Sciences, Tehran, Iran. Tel: +98.9127212071, Email: manigeh.naderi@gmail.com

Received: August 23, 2016, Accepted: September 22, 2016, Published: January 2017

iThenticate screening: September 15, 2016, English editing: December 23, 2016, Quality control: January 06, 2017 (C) 2017 The Authors. This is an open access article under the terms of the Creative Commons Attribution-NonCommercialNoDerivs License, which permits use and distribution in any medium, provided the original work is properly cited, the use is non-commercial and no modifications or adaptations are made. 
very important in the nursing profession; because the time wasted by nurses, is the time not spent with the patient and it has a negative effect on the quality of care given to patients (6). Recent changes in hospital caregiving have been effective on the work of nurses and the time used by them (7). It suggests that nurses are required to work more strictly and smartly due to long work hours in order to carry out more of their day to day tasks, in a limited time (8). Learning time management skills in academic years, is necessary for nurses in order to obtain essential qualifications for entering the clinical setting, and offering high quality service in the future (9). Effective application of time management skills associates with academic achievement $(2,10-13)$, stress reduction (11, 14, 15), increased creativity (16), self-efficiency (17), and satisfaction of students (18). Time management skill is one of the criteria that are used by students which results in an academically successful performance; the attempt for success is called academic motivation (19). Academic motivation means internal tendency of the learner that leads them to learning, skill acquirement and academic achievement (20). Academic motivation is very important for nursing students. Reduction of motivation has adverse effects on nurses, health of patients and society, and it diminishes many assets (21). Many nursing students do not have adequate academic motivation (22), and one of the reasons can be stress and anxiety (19). Stressful clinical settings, heavy courses, learning requirements and application of new techniques for patients, relationship with different patients, fear of making mistakes due to inadequate experience and evaluation of professors, cause students to experience permanent anxiety in their academic years. This can reduce motivation, causing academic failure thus academic dropout (23). Time management is one of the ways which can be very effective on anxiety and academic motivation of students (19). However, the concept of time is outlined as a problem in socio-academic life of students (10). As a subgroup of the main sources of a treatment center, nursing students will be responsible for supplying, protecting and promoting general health; therefore, it should be given precise attention (24). According to research, students with optimal skills of time management will be able to manage time effectively even after graduation and in their professional life (10). This issue emphasizes on the necessity of time management skills in nursing students, and its related factors. In this direction, previous studies were conducted either in other countries $(9,25,26)$, or conducted on students (27). In order to address the issue, the following was set as the specific objectives of the study: 1) to determine the time management skills, anxiety and academic motivation levels of nursing students; 2) to determine the correlation between nursing students' time management skills and state-trait anxiety; and 3) to determine the correlation between nursing students' time management skills and academic motivation.

\section{Material and Methods}

\subsection{Design and setting of the research}

This cross-sectional study was conducted on nursing students in Tehran University of Medical Sciences, Shahid Beheshti University of Medical Sciences, and Iran University of Medical Sciences during the 3-month period from November 2015 through January 2016.

\subsection{Sample size and sampling}

A stratified sampling method was used, and the samples were stratified according to the three medical sciences universities included in the study population. Since there was no similar study, and in order to determine the sample size, correlation coefficient between time management and anxiety was - 0.22 and it was 0.14 between time management and academic motivation, using results of a preliminary study. Given $r=0.14, \alpha=0.05$, and $\beta=0.2$, the sample size was 398 individuals. The final sample size was considered as 441 individuals concerning the percent of non-response (11\%). On average, 200, 180 and 61 students were selected randomly from Shahid Beheshti, Tehran and Iran universities of medical science respectively ( $50 \%$ of the nursing students of each university).

\subsection{Inclusion \& exclusion criteria}

Inclusion criteria were being a student from third to sixth semester of nursing field of study and exclusion criteria were being a guest student, having a mental disease or well-known anxiety disorder. The reason for choosing students from third to sixth semester was their entrance into clinical settings along with learning theoretical courses in the faculty, in order for the samples to become homogenous.

\subsection{Data collection tools}

The data were collected using Demographic Questionnaire, Time Management Questionnaire (TMQ), Spielberger State-Trait Anxiety Inventory (STAI) and Academic Motivation Scale (AMS) that was completed by self-report. The Demographic Questionnaire was prepared as an instrument to collect relevant information on intervening variables, including the students' age, gender, semesters of academic year, marital status, number of children, job status, place of living and mean score. The Time Management Questionnaire developed by Britton and Tesser 
(1991) is made up of 18 items in the short-range planning dimension (7 items), time attitudes dimension (6 items), and long-range planning dimension (5 items). Each item answered on a five-point Likert scale consisting of the responses: always (5), frequently (4), sometimes (3), infrequently (2), and never (1). The range of possible scores was18- 90 on the 18-item Time Management Scale; Points below 46 indicated low-level, points between 46 and 58 indicated moderate-level, and points 58 and above indicated high-level of time management skills. State-trait anxiety inventory (STAI) developed by Spielberger (1970), consisted of forty statements in two State anxiety subscale (items 1-20), and Trait anxiety subscale (items 20-40). Each STAI item was given a weighted score of 1-4. The range of possible scores was 0-80; Points between 0 and 20 derived from both subscales indicated no anxiety, points between 20 and 40 indicated low-level of anxiety; points between 40 and 60 indicated mid-level anxiety; and points between 60 and 80 indicated severe anxiety levels. The Academic Motivation Scale (AMS) developed by Vallerand et al. (1992), consists of 28 items on five-point Likert scales from completely disagree (1 score) to completely agree (5 scores). AMS consisted of three subscales: Extrinsic motivation subscale (12 items), intrinsic motivation subscale (12 items) and amotivation subscale (4 items). The range of possible scores was $28-140$ on the 28-items Academic Motivation Scale; points between 28 and 56 indicated amotivation, points between 56 and 84 indicated low-level, points between 84 and 112 indicated moderate-level, and points between 112 and 140 indicated high-level of AMS. In the current study, Cronbach's alpha for TMQ and AMS with good internal consistency were 0.75 and 0.89 respectively. Also, Cronbach's alpha values were 0.91 for the State anxiety subscale and 0.87 for the Trait anxiety subscale. The qualitative face validity of tools was confirmed by 15 members of the faculty members of Shahid Beheshti University of Medical Sciences.

\subsection{Ethical considerations}

This study was approved by the Ethics Committee of Nursing \& Midwifery School of Shahid Beheshti University of Medical Sciences with the registration number of IR.SBMU.PHNM.1394.201 in Dec 14, 2015. All of the subjects were informed regarding the details of the study, and they signed a written informed consent.

\subsection{Statistical analyses}

Data were analyzed using SPSS 18 software with descriptive and analytical statistics such as ANOVA, independent t-test, Regression and Pearson Correlation Coefficient.

\section{Results}

In present research, 441 nursing students participated and their ages were between 19 and 34 years old with mean of 22.01 years $( \pm 3.1)$. Most students were female $(60 \%)$, who were studying in the third semester $(33 \%)$, unemployed (63\%), single (84\%) and most of the married students had no children (96\%). The mean total average of students in the last academic semester was $15.99( \pm 1.33)$. The majority of students were living with their families $(68 \%)$. In direction of the first research goals, the mean time management skill of students under study was $57( \pm 8.27)$ scores from 90, meaning that most of them (49\%) were at moderate level. Also, the mean score of state anxiety and trait anxiety of nursing students who participated in the study was $43.98( \pm 9.55)$ and $43.19( \pm 8.57)$ respectively, from 80 scores; such that the majority of students were at mid-level of state and trait anxiety ( $58 \%$ and $60 \%$ respectively). Mean score of academic motivation of students was $108( \pm 14.02)$ and most of them were at moderate level of academic motivation (58\%). In direction of the second research goals, there was a negative and significant correlation between time management skill with state $(r=-0.282, p<0.001)$, and trait $(r=-0.325, p<0.001)$ anxiety of nursing students. It means that the increasing degree of time management skill reduces state-trait anxiety and vice versa. In direction of the third of the research goals, Pearson test showed positive and significant correlation between time management skill and academic motivation of students. Such that the increasing degree of time management skill increases academic motivation and vice versa $(\mathrm{r}=-0.279, \mathrm{p}<0.001)$.

\section{Discussion}

Results showed that about half of the nursing students were at a moderate level of time management skill. This finding was consistent with the results of Ocak and Boyraz (28), Kaya et al. (10) and Dalir et al. (29). Parallel to this study, the findings obtained from another study conducted by Kebriaei et al. (18) on students of Zahedan University of Medical Science and those conducted by Koushan and Heydari (30), on students of Sabzevar University of Medical Science revealed a moderate level of time management skill. In the study conducted by Hosseini et al. (31) on study skills of bachelor students in the Yazd School of Public Health, the lowest score of study skill associated with time management. According to results, it can be said that nursing students require more programs for learning time management. According to results of the study, most of the nursing students possessed mid-level anxiety score (either state or trait anxiety) generally. This result was consistent with studies of Bayoumi et al. (23), Gasemnegad \& 
Barkhordari (32) and Taghavi Larijani et al. (33), that suggested mid-level of anxiety scores among students. Uncontrollable anxiety of one nursing student can lead to academic failure and dropout of the student; furthermore, negative consequences can create problems for his/her family, classmates and clients. Nursing is one of the most sensitive, stressful and challenging jobs and it requires a stable, calm mind. Nurses should be able to control their feelings in order to increase their accuracy and speed in a practice that, due to sudden work stresses or critical conditions, would otherwise prevent them from making crucial decisions more precisely. . Anxiety is considered as a factor that disturbs mental regulation and stability and it prevents from coping with sensitive conditions and reasonable reactions (34). Therefore, nursing students should learn skills to control anxiety, and should practice them frequently in order to deal with non-optimal conditions in practice and in their future professions. Evidence of the study emphasizes on necessity of teaching skills of anxiety management to nursing students. According to research findings, most of the nursing students were at the moderate level of academic motivation. Similar to our study findings, the study conducted by Vahedi et al. (21) and Dalir et al. (29) on nursing students in Tabriz \& Mashhad, and also researches of Rouhi et al. (35) and Nuhi et al. (36) on students of Golestan University of Medical Sciences and Baqiyatallah University of Medical Sciences, showed that the academic motivation of students was average and higher. In the research conducted by Sharififard et al. (37), 23.6\% of nursing and para medical students had high level of amotivation. An unmotivated student has a considerably adverse effect on their classmates due to their uninterested and unmotivated behavior even if they continue their study. Any factor that reduces individual motivation will reduce system dynamics, and will make success and advancement difficult. It is while these students are educated for settings where working is affected directly by individual and human motivations. Therefore, risks of lack of motivation in nursing students are more difficult and sensitive than other things and it is clear that educational authorities should take measures to promote and reinforce motivation in nursing students. Research results showed negative and significant correlation between time management skills with state-trait anxiety of students. This was similar to the finding of Kaya et al. (9) on nursing \& midwifery students of Turkey and results of Eldeleklioglu (38) which indicated the negative and significant relationship between time management and anxiety. Al Khatib (10) reported a negative and significant relationship between stress and time management in students of the University of Science and Technology in The United Arabic Emirates. However, Wahat et al. (15) showed no relationship between time management and stress in students of Speech Sciences University in Malaysia, and the reason may be application of computer for curriculum and studying courses on days other than the day before the exam. According to his study, Kelly (39) stated that time management behavior cannot be merely effective on reduction of anxiety, and concern of students rather than perception of goal and time structure were more important. In addition, the positive effect of time management education on anxiety reduction in students was determined (27). According to above mentioned evidence, time management education can be used in nursing faculties to overcome students' anxiety. In this direction, educational authorities require planning for practical workshops and programs to teach time management and to prioritize anxious students. The present research indicated a significant and positive relationship between time management and academic motivation of nursing students. It shows that academic motivation of students increases through successful control and planning of activities within time ground. Few studies have been conducted on the relationship between time management and academic motivation. Research results of Yaghoobi et al. (27) suggest positive effect of time management education on the increasing academic motivation, and they are in agreement with the present study. Concerning the role of academic motivation in students' activities and detrimental nature of lack of motivation in nursing students, all measures taken for reinforcement of academic motivation in such students, can be important and suitable. One of the partial results of this study is a reverse and significant relationship between different types of anxiety and academic motivation of nursing students, meaning that anxious students have lower motivation for continuing their study. This result was consistent with the study of Yaghoobi et al. (27), who indicated negative and significant relationship between anxiety and academic motivation. This research showed that if we teach time management skill to students, academic anxiety, as one of the most important factors of lack of motivation for studying, will be removed and we will face calmer and more motivated nursing students. Many researchers conducted studies to find factors affecting motivation, and a considerable collection of reinforcing and weakening factors of motivation has been yet identified (26). The present research emphasized on the reverse relationship between anxiety and academic motivation on one hand and direct relationship between time management skill and academic motivation on the other hand, and it defined two important reinforcing and weakening factors of motivation among nursing students. Therefore, it has provided a practical guide for educational policymakers in this field. Limitations of this study were the high number of research variables, multidimensionality of the research, the ability and time limitation of the researcher for counting all variables and related factors on one hand and collecting data as self-report and high number of questionnaires on the other hand. 


\section{Conclusions}

In summary, results of the present study show a moderate level of time management skill, anxiety and academic motivation in nursing students, and also a positive and significant correlation between academic motivation and time management skill, and negative correlation between time management skill and overt-covert anxiety of nursing students. Such results indicated that managers of nursing faculties should identify related factors, promote mental health of nursing students and educate an efficient human source. It is suggested that some researches are conducted on components of time management skill, and variables of the present study are investigated more comprehensively by other tests such as factor analysis.

\section{Acknowledgments:}

The present paper was derived from M.S thesis approved by research committee of Shahid Beheshti University of Medical Sciences in Tehran (No: 7347). The researchers would like to thank the authorities of nursing \& midwifery faculties of Tehran, Shahid Beheshti and Iran and also the nursing students who participated in the research.

\section{Conflict of Interest:}

There is no conflict of interest to be declared.

\section{Authors' contributions:}

All authors contributed to this project and article equally. All authors read and approved the final manuscript.

\section{References:}

1) Qaed Mohammadi MJ, Nazem F. The relationship between entrepreneurship and university students' time management in islamic azad university. Educational administration research quarterly. 2011; 2(4(8)): 91 104.

2) Pehlivan A. The effect of the time management skills of students taking a financial accounting course on their course grades and grade Point averages. International Journal of Business and Social Science. 2013; 4(5): 196-203.

3) Marquis BL, Huston CJ. Leadership Roles and Management Functions in Nursing. 7th ed. Philadelphia: Lippincott; 2012.

4) Finkelman AW. Leadership and Management in Nursing. New Jersey: Pearson Prentice. 2006; 412-13.

5) Ravari A, Alhani F, Anoosheh M, Mirzaie-Khalilabadi T. The pattern of time management in college students of Kerman University of Medical Sciences in the year 2006. Iran South Med J. 2008; 11(1): 76-84.

6) Nasri Sh, Pazargadi M, Zagheri Tafreshi M, Nassiri N. The Correlation of Head Nurses' Time Management with Nurses' Job Satisfaction in Medical \& Surgical Wards of Hospitals in Arak Medical Sciences University. Journal of Nursing and Midwifery. 2013; 22(79): 1-7.

7) Duffield C, Gardner G, Catling-Paull C. Nursing work and the use of nursing time. J Clin Nurs. 2008; 17(24): 3269-74. doi: 10.1111/j.1365-2702.2008.02637.x. PMID: 19146585.

8) Tomey AM. Guide to Nursing Management and Leadership. 6th ed. St. Louis: Mosby; 2008; 120.

9) Kaya H, Kaya N, Palloş AÖ, Küçük L. Assessing time-management skills in terms of age, gender, and anxiety levels: A study on nursing and midwifery students in Turkey. Nurse Educ Pract. 2012; 12(5): 2848. doi: 10.1016/j.nepr.2012.06.002. PMID: 22727849.

10) Al Khatib AS. Time management and its relation to students' stress, gender and academic achievement among sample of students at Al Ain University of science and technology, UAE. International Journal of Business and Social Research (IJBSR). 2014; 4(5): 47- 58.

11) Tanriogen A, Iscan S. Time management skills of Pamukkale University students and their effects on academic achievement. Eurasian Journal of Educational Research (EJER). 2009; 35: 93-108.

12) Britton BK, Tesser A. Effects of time management practices on college grades. Journal of Educational Psychology. 1991; 83(3): 405-10. doi: 10.1037/0022-0663.83.3.405.

13) Jahanseir K, Salehzadeh K, Vesagi H, Mosavifar A. A Study of the Effect of Time Management on Academic Achievement of Students of Islamic Azad University Maragheh Branch. Research in Curriculum Planning. 2008; 1(16): 97-114.

14) Misra R, McKean M. College students' academic stress and its relation to their anxiety, time management, and leisure satisfaction. American Journal of Health Studies. 2000; 16(1): 41-51.

15) Wahat NHA, Saat NZM, Ching CK, Qin LY, May GC, Omar N, et al. Time Management Skill and Stress Level Among Audiology and Speech Sciences Students of Universiti Kebangsaan Malaysia. Procedia Social and Behavioral Sciences. 2012; 59: 704-8. 
16) Yaghoobi A, Mohagheghi H, Mottaghian M. The role of gender, academic discipline and time management in predicting students' verbal creativity at Bu-Ali Sina. Journal of Innovation and Creativity in Human Science. 2013; 3(1): 39-54.

17) Terry KP, Doolittle PE. Fostering self-efficacy through time management in an online learning environment. Journal of Interactive Online Learning. 2008; 7(3): 195-207.

18) Kebriaei A, Sabahi Bidgoli M, Saeedi A. Relationship between use of time management skills and satisfaction with spending time among students of Zahedan university of medical sciences. Journal of Medical Education Development. 2014; 6(12): 79-88.

19) Omidvar H, Omidvar Kh, Omidvar A. The determination of effectiveness of teaching time management strategies on the mental health and academic motivation of school students. Journal of school psychology. 2013; 2(3): 6-12.

20) Roshan Milani S, Aghaii Monvar I, Kheradmand F, Saboory E, Mikaili P, Masudi S, et al. A study on the academic motivation and its relation with individual state and academic achievement on basic medical students of Urmia university of medical sciences. J Urmia Nurs Midwifery Fac. 2011; 9(5): 357-66.

21) Vahedi S, Esmaeel Poor K, Zamanzadeh V, Ataee Zade A. The nursing students' motivational profile and its relationship to their academic achievement: A person-oriented approach. Quarterly Journal of Nersing Management. 2012; 1(1): 36-46.

22) Adib haj bagheri M, Dianati M. The Compatibility of Students' Personality for Studying Nursing and Working in their Profession. Iranian Journal of Medical Education. 2004; 4(2): 5-11.

23) Bayoumi MMM, Elbasuny MMM, Mofereh AM, Assiri MAM, Al Fesal AH. Evaluating nursing students' anxiety and depression during initial clinical experience. international journal of psychology and behavioral sciences (IJPBS). 2012; 2(6): 277-81. doi: 10.5923/j.ijpbs.20120206.12.

24) Oudi D, Nasiriforg A, Pasban F, Kianfar S. Determining the effective factors on educational motivation in nursing students. Modern Care Journal. 2006; 3(1): 35-9.

25) Claessens BJC, Eerde WV, Rutte CG, Roe RA. A review of the time management literature. Personnel Review. 2007; 36(2): 255-76. doi: 10.1108/00483480710726136.

26) Hellsten LAM. What do we know about time management? A review of the literature and a psychometric critique of instruments assessing time management, Time Management. Prof. Todor Stoilov (Ed.), InTech. 2012; 1-28. doi: 10.5772/37248.

27) Yaghoobil A, Mohagheghi H, Yousef Zade M, Ganji K, Olfatii N. The effect of time management training on test anxiety and academic achievement motivation among high school students. Journal of school psychology. 2014; 3(1): 145-53.

28) Ocak G, Boyraz S. Examination of the Relation between Academic Procrastination and Time Management Skills of Undergraduate Students in Terms of Some Variables. Journal of Education and Training Studies. 2016; 4(5): 76-84. doi: 10.11114/jets.v4i5.1313.

29) Dalir Z, Shojaeean Z, Khodabandehloo Z. Survey on the Motivation of Nursing and Midwifery Students toward Their Field of Study Selection- Nursing and Midwifery School-1387. IJNR. 2011; 6(20): 44-51.

30) Koushan M, Heydari A. Study habits in students of Sabzevar school of medical sciences. Journal of Sabzevar University of Medical Sciences. 2006-2007; 13(4(42)): 185-9.

31) Hosseini MH, Ahmadieh MH, Abbasi Shavazi M, Eslami Farsani S. Study Skills in Bachelor Students in the School of Public Health, Yazd, 2006. Strides Dev Med Educ. 2009; 5(2): 88-93.

32) Barchordary M. Frequency of anxiety and its relation with depression and other individual characteristics in nursing students. Holistic Nursing and Midwifery. 2012; 22(2): 40-7.

33) Taghavi Larijani T, Sharifi Neiestanak N, Aghajani M, Mehran A. Assertiveness and Anxiety in Midwifery \& Nursing Students. Hayat. 2009; 15(2): 61-72.

34) Hasanpour Dehkordi A, Masoudi R, SalehiTali S, Frouzandeh N, Naderipour A, Pourmirzakalhori R, et al . The effect of progressive muscle relaxation on anxiety and stress in nursing students at the beginning of the internship program. J Shahrekord Univ Med Sci. 2009; 11(1): 71-7.

35) Rouhi G, Hoseini SA, Badeleh MT, Rahmani H. Educational motivation and its relationship with some factors among the students of Golestan University of Medical Sciences. Strides Dev Med Educ. 2008; 4(2): 77-83.

36) Nouhi S, Hoseini M, Rokhsarizadeh H, Saburi A, Alishiri G. Progress Motivation among Baqiyatallah University of Medical Sciences Students and Its Relationship with Academic Achievement. J Mil Med. 2012; 14(3): 200-4. 
37) Sharififard F, Asayesh H, Nourozi K, Hosseini MA, Taheri Kharameh Z. The Relationship between Motivation and Academic burnout in Nursing and Paramedical Students of Qom University of Medical Sciences, Iran. Qom Univ Med Sci J. 2016; 9(12): 72-8.

38) Eldeleklioğlu J. Investigation of adolescents' time-management skills in terms of anxiety, age and gender variables. Elementary Education Online. 2008; 7(3): 656-63.

39) Kelly WE. No time to worry: the relationship between worry, time structure, and time management. Personality and Individual Differences. 2003; 35(5): 1119-26. doi: 10.1016/S0191-8869(02)00322-7. 